\title{
POLÍTICAS DA EDUCAÇÃO E SISTEMAS FILOSÓFICOS: A VONTADE DA EXCLUSÃO
}

\author{
ROSELY GIORDANO*
}

\begin{abstract}
Perseverando em desempenhar as funçôes de sacerdotes leigos da palavra de Zeus (...) não descreram da capacidade humana de obter, através da simples reflexão, conhecimentos seguros e absolutos, suscetiveis de exprimir-se num discurso que traduzisse uma intuição divina. Assim procedeu a filosofia clássica grega, assim procederam os grandes sistemas dogmáticos do helenismo, assim os imitaram as filosofias medieval e moderna: também sob esse prisma, não há como recusar razão a Heidegger, quando nos diz que a filosofia é grega na sua essência e que a expressão "filosofia européia ocidental" é uma tautologia. (Porchat, 1981, p. 11; grifos meus)

Nunca houve um monumento da cultura que não fosse também um monumento da barbárie. E, assim como a cultura não é isenta de barbárie, não o é, tampouco, o processo de transmissão da cultura. (Benjamin, 1993, p. 225; grifos meus)
\end{abstract}

RESUMO: Neste texto se trava, com auxílio dos pensadores de Frankfurt, Adorno e Horkheimer, uma luta frontal contra o pensamento que unifica, exclui e reduz os outros pensares. Para isso, a categoria de "experiência" desempenha um papel principal: um exercício do (com)partilhar com o diferente, abdicando da dominação, em busca constante da extensão do movimento do esclarecimento, da autonomia e da emancipação social e política.

Palavras-chave: Pensamento. Exclusão. Diferença. Esclarecimento.

\section{EDUCATIONAL POLITICS AND PHILOSOPHICAL SYSTEMS: THE WILL OF EXCLUSION}

ABSTRACT: This paper braces, with the help of the thinkers from Frankfurt: Adorno and Horkheimer, a frontal battle against the thought that unifies, excludes and reduces the other thoughts. For

* Professora da Universidade Federal do Pará (UfPA).E-mail: philosophi@uol.com.br 
this, the category of experience plays the main role: an exercise of sharing with the different, abdicating of domination, in constant search of the full enlightenment movement of the autonomy and the social and political emancipation.

Key words: Thought. Exclusion. Difference. Enlightenment.

Tr ste ensaio, de natureza filosófica, tem como pano de fundo a controvérsia instituída pelos contornos das atuais políticas públicas da educação e, em particular, as voltadas ao ensino da filosofia. No interior deste contexto, problematizo a especificidade da educação (em particular, na contemporaneidade), da filosofia e de seu ensino, pois que, tendencialmente, refletem a vontade da exclusão, sendo, ainda, conforme as proposições de Nietzsche, instrumentos, não da cultura, mas da miséria do viver. Essa vontade (consubstanciada nas relações de poder instituídas, quer pela hegemonia, quer pela força) - inspirada nas políticas da educação "esclarecidas", que afirmam buscar um saber e um fazer comprometidos com a promoção da autonomia - instala-se entre nós, determinando, por sucessivas mediações, desde as relações que estabelecemos na academia às nossas práticas em sala de aula e os conteúdos e programas "ensinados" como meios para um fazer educativo que, embora prescrevam a liberdade, a emancipação e a autonomia, instauram e reforçam, ao contrário, o autoritarismo e a heteronomia sociais.

Busco, outrossim, verificar de que forma também nas relações tecidas entre a filosofia e sua própria história, consolidada em suas diferentes concepções e sistemas, manifesta-se, no seio da sociedade que as engendra - tal como nas políticas da educação -, a mesma vontade da exclusão, que permeia, predominantemente, os sistemas filosóficos.

Ao esquadrinharmos a tessitura da lógica do saber científico e, particularmente, a do saber filosófico triunfantes na história do pensamento, desvela-se - em meio à trama de conceitos que, no interior de uma certa ordem de razões, constituem os diferentes sistemas filosóficos - a patologia constitutiva do que, historicamente, erguemos, ao longo do processo civilizatório, como sendo a racionalidade, dada a pretensão, vivificada por parte de alguns desses sistemas, de constituírem-se em verdades únicas e universais e, portanto, excludentes de outras verdades, outras filosofias.

Quem hoje em dia escolhe o trabalho filosófico como profissão, deve, de início, abandonar a ilusão de que partiam antigamente os projetos filosóficos: 
que é possível, pela capacidade do pensamento, se apoderar da totalidade do real. Nenhuma razão legitimadora poderia se encontrar novamente em uma realidade, cuja ordem e conformação sufoca qualquer pretensão da razão; apenas polemicamente uma realidade se apresenta como total a quem procura conhecê-la, e apenas em vestígios e ruínas mantém a esperança de que um dia venha a se tornar uma realidade correta e justa. A filosofia, que hoje se apresenta como tal, não serve para nada, a não ser para ocultar a realidade e perpetuar sua situação atual. (Adorno, 2004, p 1; grifos meus)

Particularizar a temática da exclusão implica, pois, movimento de insubordinação a essa patologia e, simultaneamente, tempo de busca de concepçôes outras de filosofia.

A proposição deste ensaio revela, desse modo, ela própria, uma certa concepção de filosofia, que se deixa entrever do diálogo com autores que indicam a possibilidade de um novo pensar. Dentre eles, distingui: MerleauPonty, Foucault e, principalmente, os teóricos da Escola de Frankfurt (em especial, Adorno e Horkheimer). Novo pensar, pois o pensamento filosófico, ao colocar-se sob a ótica da Teoria Crítica, por exemplo, como pensar que não está pronto e acabado, com a consciência desta provisoriedade, torna-se capaz de - afrontando aquele(s) saber(es)/poder(es) disposto(s) como conveniente(s) a ser(em) conhecido(s) - desentranhar (como nos propõe Foucault) um pensar diferentemente do que se pensa, possibilitando, ao separar-se de si mesmo, o acolher das diversidades e diferenças, em oposição à exclusão, que, para além de nuclear as formas sociais contemporâneas, encontra, como se quer demonstrar, sua justificativa teórica também na ordem das razóes de toda filosofia animada pela vontade de representar a verdadeira e última solução dos problemas do ser e do conhecer.

$\mathrm{Na}$ tentativa de resistirmos às formas dominantes do pensar/agir, questionamos, como nos instiga Foucault a refletir, a validade da necessária obstinação do saber, se este assegura apenas a aquisição dos conhecimentos e não, de certa maneira, e tanto quanto o permite, o separar-se de si mesmo, oferecendo-se, assim, aberto à diversidade de outros pensares.

Afinal, que motivo teríamos nós, cuja tarefa de vida concerne à educação, para fazermos filosofia, interpretarmos sua história, debatendo a crise da sociedade e da razão contemporâneas se - entre nós, nossos pares e os autores que lemos - buscamos o único, o idêntico e a universalidade, ao invés de colocarmo-nos abertos quer à diversidade de outros pensares, quer à de nosso próprio pensar? $\mathrm{O}$ motivo pelo qual pergunto encontra resposta na similitude, que se deixa entrever entre as palavras 
Políticas da educação e sistemas filosóficos: a vontade da exclusão

de Campos e as de Adorno, ao referirem-se à opinião, à "normalidade" do preconceito, como causas da busca da identidade, da exclusão do diferente. Cito-os:

Somos levados, impulsivamente, a repudiar tudo (...) que difere dos padrōes que introjetamos da nossa sociedade e da nossa cultura e acomodamos na nossa "normalidade" (...). À medida que começamos a conhecer e a reconhecer no estranho, no estrangeiro, no outro, as bases comuns de nossas diferenças, isto é, nossa identidade social e antropológica, verifica-se uma mudança qualitativa em nosso julgamento. Formas de comportamento (...) desvios de personalidade, passam a ter uma resposta simpática: o diferente, o estrangeiro se revelam interessantes, capazes de enriquecer o nosso "universo de respostas únicas", ou seja, a nossa pobreza cultural. (...) No limite, a paixão que obscurece as diferenças, os defeitos e que até os converte em virtudes descobertas ou imaginadas no objeto, no outro, tem um componente narcisista: amamos no outro os ingredientes nossos que imaginamos descobrir no objeto amoroso. (Campos, 2002, p. 4; grifos meus)

Mas a própria categoria de "opiniāo", como uma etapa objetiva do espírito, está encouraçada contra essa reflexão. Isso se pode explicar em razão de fatos muito simples da psicologia individual. Quem conta com uma opinião sobre uma questão que, em alguma medida, está aberta, que não está decidida de antemão e cuja resposta não se pode pôr à prova tão facilmente quanto no caso do número de pisos de um edifício, tende a afirmar-se em sua opiniāo, ou, para utilizar a linguagem da psicanálise, a apoderar-se dela emocionalmente. Seria insensato considerar-se livre dessa tendência. Provém do "narcisismo", isto é, do fato de que até hoje os homens estão obrigados a destinar uma parte de sua capacidade de amar, não à outra pessoa amada, mas a si próprios, numa forma reprimida, inaceitável e, portanto, venenosa de amar. (Adorno, 1969, p. 140; grifos meus)

\section{Das políticas da educação às teorias e práticas filosóficas: a miséria do viver}

Por mim, não conheço senão uma verdadeira oposição, aquela dos estabelecimentos da cultura e dos estabelecimentos da miséria de viver: é à segunda categoria que pertencem todos aqueles que existem, mas é da primeira que falo. (Nietzsche, 1975, p. 134; grifos meus) ${ }^{1}$

O texto da Lei de Diretrizes e Bases da Educação Nacional (LDBEN n. 9.394/96), ao propor a educação como processo que "(...) abrange os pro- 
cessos formativos que se desenvolvem na vida familiar, na convivência humana, no trabalho, nas instituiçōes de ensino e pesquisa, nos movimentos sociais e organizaçōes da sociedade civil e nas manifestações culturais" (Brasil, 1997, p. 1), ilumina as relações de pertença e determinação entre $e d u$ cação e sociedade, permitindo-nos reafirmar que as políticas educacionais só podem ser compreendidas por referência aos fatores socioeconômicos da sociedade brasileira, erguida, historicamente, sobre o princípio da heteronomia social, princípio que só se perfaz por meio de um processo de exclusão autoritária e sistemática do "diferente", do desigual.

Dada a alienação, instaurada pela transposição mediata dos gestos e atos fabris às ações e relações sociais, que se nos impõe na cotidianidade, movo-me pela injunção da apreensão das singularidades do objeto que aqui se quer compreender, no sentido de tornar possível - pela construção histórica das formas mercadoria e valor de troca - iluminar de que modo o Estado neoliberal, precisamente, ao subtrair-se, em larga escala, do financiamento das políticas públicas, em particular das da educação ${ }^{2}$ e da saúde, determina (a) a situação de falência em que estas se encontram, em âmbito nacional; (b) o condicionamento do desenvolvimento educacional, em todos os seus níveis, aos ditames das agências financeiras dos mercados nacional e internacional; ${ }^{3}$ bem como (c) a mercantilização da cultura, em virtude de a estrutura das formações econômicas capitalistas erguer-se, por princípio, sobre a lógica do capital, cuja ordem jurídica estabelece o direito - e a naturalidade deste - à apropriação privada dos bens materiais e espirituais. As estruturas sociais hodiernas assentadas nos "pecados do capital”, tal como exposto, tornam inteligível o argumento apresentado por Paulo Renato Souza e Fernando Henrique Cardoso, quando alegaram o ônus financeiro para os estados e o Distrito Federal a pretexto de vetarem o Projeto de Lei n. 3.178/97 - aprovado, por ampla maioria, na Câmara dos Deputados e no Senado Federal -, que incluía a obrigatoriedade das disciplinas de Sociologia e Filosofia no ensino médio. Contrariaram, pois, a própria $\mathrm{LDB}$ que prevê, com a finalidade do “(...) aprimoramento do educando como pessoa humana, incluindo a formação ética e o desenvolvimento da autonomia intelectual e do pensamento crítico", o "domínio dos conhecimentos de Filosofia e de Sociologia necessários ao exercício da cidadania” (Brasil, 1997, p. 15). ${ }^{4}$

Cumpre, pois, ressalvar o agravamento imposto pela política socioeconômica em curso, que, salientando as desigualdades sociopolíticas, sublinha os mal-estares em meio a populações, desde tempos coloniais, já 
desfavorecidas. Desvalidos, pois, da esperança de invertermos esses constrangimentos que se nos impóem, dado estarmos, conforme nos indica Martins (1996, p. 35-36), “(..) aparentemente condenados ao tempo trágico do 'atual' e do imediato, ao tempo da falta de imaginação e da falta de esperança" e, por este motivo, vendo parte de nossa vida cotidiana tornar-se "(...) desesperada busca de sentido 'aparente' para o que fazemos ou para o que acontece conosco e ao nosso redor", justifica-se a necessidade de, continuamente, pensarmos as determinaçôes reais das atuais políticas da educação. Mas pensarmos a partir do lugar da experiência, por ser a experiência do sujeito cognoscente a essência do pensamento filosófico, ao contrário do disposto pela disciplina científica em voga, coágulo do pragmatismo, que - ávida da objetividade imediatamente palpável, preferencialmente sob a forma do lucro - se quer excludente da subjetividade do sujeito o qual, assim procedendo, pensa, apenas, o já pensado. Como que a impelir o movimento do pensar, opondo-se à reprodução do pensamento já instituído, a própria experiência auxilia-nos, conforme assinala Thompson (1981, p. 17):

A experiência não espera discretamente, fora de seus gabinetes, o momento em que o discurso da demonstração convocará a sua presença. A experiência entra sem bater à porta e anuncia mortes, crises de subsistência, guerra de trincheira, desemprego, inflação, genocídio. Pessoas estão famintas: seus sobreviventes têm novos modos de pensar em relação ao mercado. Pessoas são presas: na prisão, pensam de modo diverso sobre as leis. Frente a essas experiências gerais, velhos sistemas conceptuais podem desmoronar e novas problemáticas podem insistir em impor sua presença. (...) fora dos recintos da universidade, outro tipo de produção de conhecimento se processa o tempo todo. Concordo em que nem sempre é rigoroso. Não sou indiferente aos valores intelectuais nem inconsciente da dificuldade de se chegar a eles. Mas devo lembrar a um filósofo marxista que conhecimentos se formaram, e ainda se formam, fora dos procedimentos acadêmicos. E tampouco eles têm sido, no teste da prática, despreziveis. Ajudaram homens e mulheres a trabalhar os campos, a construir casas, a manter complicadas organizaçôes sociais, e mesmo, ocasionalmente, a questionar eficazmente as conclusões do pensamento acadêmico. (Grifos meus)

Afirmo, pois, a necessidade de um olhar que, penetrando no singular, mergulhando nas aparências, portanto na atualidade da desagregação do sujeito e da negatividade da cultura, possa emergir do imediatismo dos fatos isolados, apreendendo-lhes as relações e pertenças, pois, nas palavras de Adorno, 
(...) quem quiser saber a verdade acerca da vida imediata tem que investigar sua configuração alienada, investigar os poderes objetivos que determinam a existência individual até o mais recôndito nela. (1993, p. 89; grifos meus)

Os pensamentos que são verdadeiros devem renovar-se incessantemente pela experiência da coisa, a qual, não obstante, só neles recebe sua determinação. (...) Pensar filosoficamente é, assim, como que pensar por intermitências, ser perturbado por aquilo que o pensamento não é. (...) Onde o pensamento filosófico, mesmo em textos importantes, não atinge o ideal de incessante renovação a partir da coisa sucumbe. (...) A força do pensamento de não nadar a favor da própria corrente é a de resistir contra o previamente pensado. (1995, p. 21; grifos meus)

Ou no dizer de Nietzsche (1975, p. 277-278):

(...) e do mesmo modo que todo carregador quer também ter seu admirador, o homem mais notável, o filósofo, imagina ele próprio ter também os olhos do universo apontados como um telescópio sobre sua ação e seu pensamento (...). Este orgulho ligado ao conhecimento e à percepção anuvia e ofusca o olhar e os sentidos dos homens, engana-os sobre o valor da existência na medida em que se acompanha da apreciação mais favorecida sobre o próprio conhecimento. Seu efeito mais corrente é a ilusão (...). Como meio de conservação do indivíduo, o intelecto desdobra o essencial de suas forças na dissimulação (...). É entre os homens que esta arte de dissimulação alcança seu ponto culminante (...). Eles estão profundamente mergulhados nas ilusôes e nos sonhos, seus olhares não penetram senão a superfície das coisas e não vêem senão "formas", sua percepção não conduz de maneira alguma à verdade, mas limita-se a receber as excitações e brinca, por assim dizer, às cegas, nas costas das coisas.

Move-me, portanto, a intenção de indicar bases epistemológicas em razão do atual estado de alienação da consciência, para examinarmos as políticas da educação, pensando, no interior deste contexto, das finalidades da educação e da filosofia às distintas concepções de filosofia, no sentido de sugerir caminhos para o ensino e a pesquisa em filosofia, que possibilitem interposições para superarmos o que, com a ajuda de Nietzsche, propus como miséria do viver. Miséria caracterizada pela desagregação da cultura e do indivíduo, cujas ações, desprovidas do pensar reflexivo, revelam-nos despossuídos de autonomia, moldados, do corpo à alma, pela esfera da produção material. Atuamos nesse palco, encenando um espetáculo em que atores e platéia fundem-se em um único papel: o de representar, sem saber que o representamos, um script escrito e 
Políticas da educação e sistemas filosóficos: a vontade da exclusão

dirigido pelos que se outorgam o direito de orientar nossas consciências (orientação que, lembrando o Discurso sobre a servidão voluntária, de La Boétie, parece-nos assimilada e consentida).

Justifica-se, desse modo, que, nas falas dos educadores e de seus "discípulos", nos currículos das universidades e nos discursos de autoridades na legislação que decretam para "administrar" a educação brasileira -, encontremos palavras carentes de sentido real, tais como cidadania, democracia, ética, respeito pela pessoa, ${ }^{5}$ pois encontramo-nos desapossados da autodeterminação que nos originaria como sujeitos, cidadãos de fato, ao invés de, se e quando se observa o Estado de direito, ${ }^{6}$ sermos apenas sujeitos e cidadãos no plano jurídico.

Do interior do cenário que esbocei, que finalidades podemos atribuir, hoje, à educação? Tomo, a título de mais um exemplo, para refletir sobre esta questão, o disposto na LDBEN/96 sobre a formação dos profissionais da educação. Propondo como fundamento para a formação destes a relação entre teoria e prática, lê-se no referido título:

A formação de profissionais da educação (...) terá como fundamentos: I a associação entre teorias e práticas, inclusive mediante a capacitação em serviço; II - aproveitamento da formação e experiências anteriores em instituições de ensino e outras atividades. (...) A formação de docentes para atuar na educação básica far-se-á em nível superior, em curso de licenciatura, de graduação plena, em universidades e institutos superiores de educação, admitida, como formação mínima para o exercício do magistério na educação infantil e nas quatro primeiras séries do ensino fundamental, a oferecida em nível médio, na modalidade Normal. (Brasil, 1997, p. 24; grifos meus)

A concepção que preside a relação, acima citada, entre teoria e prática, diluindo a prática na técnica, privilegia, em detrimento da formação teórico-crítica dos educadores, a formação técnica de profissionais "competentes e aptos" para inserirem-se no mercado de trabalho, lugar erguido, também na legislação específica da educação, como agência formadora, instância que permite a capacitação do indivíduo em serviço. A este "mercadoeducador" podemos incorporar, inclusive, as próprias instituições de ensino, pois que suas finalidades se restringem ao comércio de subprodutos culturais - refiro-me, principalmente, às práticas das instituiçôes da rede privada do ensino, que vêm se expandindo, aceleradamente, em virtude das atuais transformações - determinadas pela política econômica - impostas à concepção do Estado-educador, e, em particular, ao aligeiramento 
imposto pelos institutos superiores de educação a uma educação já desfigurada. A educação tem sido regida pelas "novas tecnologias educacionais" que, por tão "novas", tornam quase inúteis professores, alunos e o próprio pensar, descartados que foram pelo privilégio atribuído à técnica, privilégio que se observa, de modo singular, nas modalidades de educação a distância (cursos não-presenciais e educação virtual), instrumento de sujeição do processo de produção do conhecimento à lógica binário-seqüencial, inerente à linguagem computacional, que substitui o sujeito pensante pelo usuário obediente aos procedimentos seriais ditados pela máquina. A educação vem cumprindo, desse modo, a finalidade de manter e recriar as relações de trabalho, tais como impostas pela lógica do capital, propondo um ensino em que a prática aparta a tecnologia da cultura e da ciência, abdicando da necessidade de uma educação política, que suprimisse o estado de menoridade político-cultural em que nos encontramos, insinuando, desse modo, a exigência de um projeto político e pedagógico voltado à emancipação, à urgência de resistirmos à adaptação.

Interrompo minha fala, recordando palavras de Nietzsche (1975, p. 132-133):

Mas que ninguém pense que os estabelecimentos que o auxiliam e o preparam para esse combate podem de uma maneira ou de outra ser considerados estabelecimentos de cultura no sentido sério da palavra. São as instituiçōes que fazem prevalecer a miséria da vida que prometem formar os funcionários, os negociantes, os oficiais, os comerciantes, os agrônomos, os médicos ou os técnicos. Para essas instituições são necessárias em todo caso outras leis e outras medidas para que se organizem os estabelecimentos de cultura (...). (Grifos meus)

\section{Da Filosofia e sua história: exclusão e autonomia}

Contrariamente a seus administradores, a filosofia representa, entre outras coisas, o pensamento, na medida em que este não capitula diante da divisão do trabalho dominante e não aceita que esta lhe prescreva suas tarefas. A ordem existente não compele os homens unicamente pela força física e pelos interesses materiais, mas pelo poder superior da sugestão. A filosofia não é síntese, ciência básica ou ciência-cúpula, mas o esforço de resistir à sugestão, a decisão resoluta pela liberdade intelectual e real. (Horkheimer \& Adorno, 1985, p. 227; grifos meus)

(...) como uma multiplicidade historicamente dada de filosofias, identicamente empenhadas, todas elas, na elucidação da própria capacidade de resolver essa 
Políticas da educação e sistemas filosóficos: a vontade da exclusão

questão de princípio e de executar de maneira adequada o programa que o mesmo empreendimento de autodefiniçāo implicitamente lhes traça. Essa pretensão, que lhes é essencial, leva-as necessariamente, então, a uma mútua e recíproca excomunhão e exclusão, na mesma medida em que pertence a cada filosofia o dever impor-se como a única e verdadeira filosofia (...) a história da filosofia brinda-nos com o desfile quase ininterrupto dos grandes sistemas que, uns aos outros sempre incompatíveis, apresentam-se animados, todos e cada um, da mesma pretensão de representar a verdadeira solução dos problemas do ser e do conhecer, a edição nova e definitiva da realidade. (Porchat, 1981, p. 11 e 13; grifos meus)

Os fragmentos acima revelam-nos duas filosofias, duas concepções distintas da filosofia. No primeiro, Horkheimer e Adorno colocam-nos, de um lado, diante de uma filosofia a serviço das relações de produção dominantes e de seus gestores, relaçóes que se consolidam no interior de uma determinada divisão social do trabalho e, de outro, diante de uma outra uma filosofia negativa, que, por referência à dialética negativa, tal como proposta por Adorno (cf. Dialética negativa), remete ao concreto, à experiência, como condição única da possibilidade de transcendermos as concepções filosóficas fundadas na identidade e onipotência do conceito - cujo propósito é o da instituição determinada da liberdade intelectual e real, liberdade que se realiza por meio da resistência a toda ordem que nos constranja - quer pelo poder da coação, quer pelo da sugestão - a ceder às tarefas impostas pelos administradores da estrutura socioeconômica dominante. Já no segundo fragmento, de Porchat, a filosofia se nos apresenta como um saber que - investido da especificidade de buscar sempre impor-se como único e verdadeiro - implica, necessariamente, a vontade da exclusão. Se, entretanto, orientamo-nos pelo princípio da inseparabilidade entre a filosofia e sua história, isto é, da inexistência de uma filosofia "pura" - depurada da realidade social concreta, da qual é produto e, em certa medida, produtora -, da impossibilidade da existência da filosofia fora da história - estrangeira às determinações que lhe vêm da história social, em que se consubstancia a história do pensar e, nesta medida, a da própria filosofia -, evidencia-se que as proposiçōes de Porchat, sugerindo um algo que seria próprio da filosofia e de sua história, não constituem, também, senão uma concepção de filosofia, ela própria manifestação das formas políticosociais dominantes, e, simultaneamente, justificativa teórica destas, pois, segundo o autor, é da natureza da filosofia ostentar o desejo de representar a última edição da Verdade. Cumpre, assim, recordar - em que pese não reivindicar a hipótese cética da incognoscibilidade do mundo - a denún- 
cia de Górgias: O Logos é um grande senhor, uma vez ser esta a denúncia que nos tem ocupado, nós que procuramos o contato com o ser bruto. Como afirma Merleau-Ponty (1962, p. 35), a filosofia não tem “(...) o mundo deitado a seus pés, não é um 'ponto de vista superior' de onde fosse possível abraçar todas as perspectivas locais, procura o contato do ser bruto e instrui-se igualmente junto daqueles que nunca dele se apartaram". Essa denúncia deve, portanto, ser aquela de todos que nos movemos em nome de uma filosofia animada pela vontade da pluralidade, pela vontade da não-exclusão das diversas formas do pensar; a filosofia dos que se movem pelo compromisso da não-redução de outros pensares à condição de fantasia ou loucura, pois essa redução, ao escravizar o humano ao Logos, operou ou a desqualificação das paixôes, de Eros e da subjetividade em nome da pretensão de alcançar o "Ser verdadeiro", ou a dos ideais humanistas do domínio da natureza, da emancipação moral e política do homem, terminando por congelá-los, respectivamente, na coisificação do Ser, na geometrização do espaço e na escravização do homem. Nessa medida, a filosofia, que se opóe à escuta do ser bruto e que se instrui junto daqueles que nunca dela se apartaram, não pode afastar-se dos que, segundo Chaui (1983), nunca o abandonaram - o pintor, o poeta, o revolucionário e, em certos casos, o cientista.

Cumpre, pois, perguntar que filosofia, que história da filosofia ler, contar, escrever, dado que

A sofística, o ceticismo e outros movimentos do pensamento posterior que se lhes pudessem assemelhar parecem constituir tão-somente momentos "relativamente apagados da reflexão filosófica" ao longo dos séculos, que apenas merecem um lugar secundário - quando o merecem - nos manuais de história da filosofia e nos programas universitários em que a filosofia se diz transmitida e ensinada. (Porchat, 1981, p. 12)

Arrisco uma "resposta", pois a filosofia, mesmo quando pretende afirmar-se como "um saber da pergunta", da interpretação, indica sempre um caminho, ao trazer subjacente às perguntas que se coloca uma certa concepção de homem, de sociedade.

Cabe-nos, quer me parecer, não nos furtarmos aos caminhos que não excluam, por parte do sujeito, a busca e a experiência do objeto real, no sentido de não nos aprisionarmos em uma Verdade, anulando, pois, outras verdades, reduzindo-as a sistemas conceptuais excludentes, que nulificam a experiência, o vir-a-ser. Seria esta a filosofia negativa, que, provisoriamen- 
Políticas da educação e sistemas filosóficos: a vontade da exclusão

te, proponho. Uma "resposta", um convite à experiência, ao mergulho no sensível, em uma racionalidade que não exclua a subjetividade, o tempo, as junturas da história.

O mundo, para além dos neuróticos, conta com um bom número de racionalistas que são um perigo para a razão viva. E, pelo contrário, o vigor da razão está ligado ao renascimento de um sentido filosófico que, se decerto justifica a expressão crítica do mundo, instala-a na sua ordem, no lugar que lhe cabe dentro do todo do mundo humano. (Merleau-Ponty, 1962, p. 299)

A experiência é intolerável, salvo se recorremos ao ardil da palavra e interpomos entre nós, como terceiro, um domínio comum de pensamento. (...) A visão alcança o que jamais a reflexão compreenderá: faz com que o combate termine às vezes sem vencedor, e o pensamento sem titular a partir de então. Olho-o. Ele vê que o olho. Vejo que ele não o vê. Ele vê que eu vejo que ele o vê... A análise não tem fim, e, se fosse a medida de todas as coisas, os olhares deslizariam indefinidamente um para o outro, "nunca haveria senão um único cogito de cada vez". Ora, embora os reflexos dos reflexos vão em princípio até ao infinito, a visão faz com que as linhas saídas dos dois olhares se ajustem, e que não tenhamos não já duas consciências com a sua teleologia própria, mas dois olhares um dentro do outro, sós no mundo. A visão delineia aquilo que o desejo realiza quando expulsa dois "pensamentos" para essa linha de fogo situada entre eles, essa superfície ardente onde buscam uma consumação que seja única e idêntica para ambos, como o mundo sensível pertence a todos. A filosofia que desvela esta encruzilhada do visível e do invisível é o perfeito contrário de um sobrevôo. Mergulha no sensível, no tempo, na história, para as suas junturas (...). (Merleau-Ponty, 1962, p. 27, 28 e 34)

Talvez esta experiência deixe de excluir aquilo que está subsumido no conceito, com o estatuto do direito à ciência: o algo que dele é distinto, diferenciado, que se deixa entrever se nos dispomos à entrega angustiante - pois, entrega ao desconhecido - do experienciar o que vive no objeto. Adorno (1995, p. 184) parece autorizar-nos a afirmar esta relação de pertença entre a filosofia que fazemos e a opinião, em função do excerto abaixo reproduzido:

Destino, a submissão à natureza dos mitos procede de uma total menoridade social, de uma época em que a autoconsciência ainda não tinha aberto os olhos, em que ainda não existia o sujeito. Ao invés de evocar o retorno daquela época, mediante a práxis coletiva, dever-se-ia extinguir o feitiço da antiga indiferenciação. Seu prolongamento é a consciência da 
identidade do espírito que, repressivamente, identifica-se ao que lhe é diverso. Se fosse permitido especular sobre o estado de reconciliação, não caberia imaginá-lo nem sob a forma de indiferenciada unidade de sujeito e objeto, nem sob a de sua hostil antítese; antes, a comunicação do diferenciado. Somente então o conceito de comunicação encontraria seu lugar de direito como algo objetivo. $O$ atual é tão vergonhoso porque trai o melhor, o potencial de um entendimento entre homens e coisas, para entregá-lo à comunicação entre os sujeitos, conforme os requerimentos da razão subjetiva. Em seu lugar de direito estaria, também do ponto de vista da teoria do conhecimento, a relação entre sujeito e objeto na paz realizada, tanto entre os homens como entre eles e o outro que não eles. Paz é um estado de diferenciação sem dominação, no qual o diferente é compartido. (Grifos meus)

Os caminhos aqui inscritos indicam a necessidade de avançarmos em direção à análise crítica, avanço que implica o tornar possível a experiência, a entrega ao objeto, superando a fixidez do conceito que o captura. Entretanto, a possibilidade da experiência - bem como a manutenção da própria vida - só é viável se se supõe algo como verdadeiro, ainda que não se saiba nada acerca desse algo. Trata-se de uma exigência da razão humana saudável, bem como do próprio instinto de conservação, o ir além do já experimentado, dado que todo pensar, válido como tal, aponta para algo que se encontra para além dos fatos que o justificam. Esta natureza do pensar se torna, contemporaneamente, mais presente, já não apenas como decorrência necessária do conteúdo e da forma adquiridos no processo de historicização dessa natureza que - em função do trato diário restrito, crescentemente, ao prático-utilitário, dados o desenvolvimento das forças produtivas e da divisão social do trabalho - entranha-se, naturalizada, no cotidiano do homem, impondo-lhe a convivência com um pensar não consciente de fatos que o justifiquem.

Estes escritos são propostos na condição de constituírem-se como se consigna para que nossas práticas - contrariamente a seguirem ignorando a exigência primeira que hoje se póe para a cultura, qual seja, a de colocarmos nossas ações e princípios, teóricos e éticos, a serviço da impossibilidade da repetição da barbárie, isto é, da danificação da cultura e da vida, no interior das instituições de ensino - estejam fundadas no exercício do (com)partilhar com o diferente, abdicando da dominação, em busca constante da extensão do movimento do esclarecimento, da autonomia e da emancipação social e política.

Recebido em maio de 2004 e aprovado em junho de 2004. 


\section{Notas}

1. Os trechos citados, seguidos do sinal asterisco, das obras referenciadas em outra língua, são traduçōes livres da autora.

2. O artigo 32, do Projeto de Lei n. 1.603/96, de iniciativa do Ministério da Educação, referente à Rede Federal de Educação Tecnológica - projeto já transformado no Decreto-Lei n. 2.208, em abril de 1997 -, é exemplo indelével desta subtração do Estado, no que concerne ao princípio da gestão pública dos recursos públicos, ao ter disposto que "O MEC 'somente' promoverá a expansão da oferta do Ensino Técnico em parceria com Estados, Municípios, Setor produtivo ou organizações não-governamentais, que serão responsáveis pela manutenção e gestão dos novos estabelecimentos educacionais" (Souza \& Silva, 1997, p. 140). Fica evidente que essas "parcerias" implicam a gestão privada dos recursos públicos e a conseqüente autonomia para a utilização destes. Autonomia que, de acordo com as concepções da face neoliberal do capitalismo, apresenta a "maior produtividade" como contrapartida para instituir as modernas estruturas organizacionais, em conformidade com os moldes empresariais.

3. Este condicionamento se evidencia, claramente, na sujeição da educação técnica e profissional aos interesses dos setores produtivos, interesses regulados pela lógica do mercado. Em que pese, portanto, a modernização crescente da tecnologia, resultante da pesquisa científica, exigir muito mais do que a simples informação e operacionalização de serviços, processos e produtos, nossos modernos tempos podem, ainda, ser iluminados pela obra catártica de Chaplin, pois, o artigo 7o, da Portaria n. 646, de 14 de maio de 1997, ao regulamentar a implantação do disposto nos artigos 39 a 42, da Lei n. 2.208/97, estatui que a oferta de cursos de nível técnico e de qualificação profissional seja feita em conformidade com as demandas identificadas junto aos setores produtivos, sindicatos de trabalhadores e sindicatos patronais, bem como junto a órgãos de desenvolvimento econômico e social dos governos estaduais e municipais, entre outros.

4. Faço, aqui, referência ao veto da obrigatoriedade da filosofia no ensino médio: “(...) o presidente da República, Fernando Henrique Cardoso, vetou o projeto de lei que tornava Sociologia e Filosofia disciplinas obrigatórias no Ensino Médio. O presidente aceitou o argumento do Ministério da Educação de que o projeto é contrário ao interesse público, uma vez que a inclusão dessas disciplinas no currículo do Ensino Médio implicaria grande ônus para os Estados, uma vez que seria necessária a criação de cargos para a contratação de professores, com o agravante de que não há no país formação suficiente de profissionais para atender a demanda" (klickeducacao.com.br, 2001; grifos meus).

5. O conceito "pessoa" implica, apesar de tão adulterado, tanto pela filosofia quanto pela psicologia personalistas, o de "autodeterminação". "Persona" era o termo romano para a máscara do teatro clássico.

6. Cumpre sublinhar a ressalva "se e quando se observa o Estado de direito", pois a última greve dos servidores públicos e, em particular, a dos docentes das universidades federais, permitiu-nos vivenciar - dentro e fora da academia - oportunidades que, para os mais observadores, desvelaram uma sociedade e, como seu espelho, uma academia cujas cúpulas dirigentes guardam, entre si, profundas semelhanças, no que concerne às concepçôes e práticas políticas. Em outras palavras, ao passo que na academia damos vida às práticas que se opōem aos ideais que anunciamos, da mesma forma, as elites dirigentes da sociedade brasileira editam "pacotes" que, contrariando, radicalmente, a Carta Constitucional (ela própria já, suficientemente, distanciada do real sentido da democracia), nos fazem não apenas 
relembrar, mas, propriamente, viver o período manifestamente ditatorial. Evidencia-se, assim, a danificação da vida e dos sujeitos, no interior de uma sociedade em que não prevalece, senão juridicamente, o Estado de direito, dado que o direito (isto é, o conjunto das normas jurídicas vigentes) é subjugado pelos referidos pacotes, ditados ao sabor da ocasião, para fazer prevalecer os interesses daqueles que - à nossa revelia e contra nossos interesses racionais e de sobrevivência - legislam e executam a lei, ou revogam suas próprias leis e descumprem-nas, alegando a existência de um sempre novo decreto, feito sob medida!, para cada nova situação que ponha em cheque as vontades contrárias do "príncipe" e de seus "súditos".

\section{Referências bibliográficas}

ADORNO, T.W. Opinión, locura, sociedad. In: ADORnO, T.W. Intervenciones: nueve modelos de crítica. Caracas: Monte Avila, 1969. p. 137-60.

ADORNO, T.W. Dialectica negativa. Madrid: Taurus, 1975.

ADORNO, T.W. De la relación entre sociología y psicología. In: ADORNO, T.W. Actualidade de la filosofía. Barcelona: Paidós/Instituto de Ciencias de la Educación de la Universidad Autónoma de Barcelona, 1991. p. 135204.

ADORNO, T.W. Minima moralia: reflexões a partir da vida danificada. São Paulo: Ática, 1993.

ADORNO, T.W. Observações sobre o pensamento filosófico. In: ADORNo, T.W. Palavras e sinais: modelos críticos 2. Petrópolis: Vozes, 1995. p. $15-25$.

ADORNO, T.W. Sobre sujeito e objeto. In: Adorno, T.W. Palavras e sinais: modelos críticos 2, Petrópolis: Vozes, 1995. p. 181-201.

ADORNO, T.W. A atualidade da filosofia. 2004. Disponível em: <http:/ /www.antivalor.kit.net/textos/frankfurt/adorno/adorno_07.htm>. Acesso em fev. 2004.

BENJAMIN, W. Sobre o conceito da história._In: Benjamin, W. Magia e técnica, arte e política. v. 1. 6._ed. São Paulo: Brasiliense, 1993. p. 222232.

BRASIL. Lei de Diretrizes e Bases da Educação Nacional. Lei n. 9.394, de 20 de dezembro de 1996. Estabelece as diretrizes e bases da educação nacional. São Paulo: Saraiva, 1997. 
Políticas da educação e sistemas filosóficos: a vontade da exclusão

CAMPOS, L. Os imperdoáveis. Tribuna da Imprensa, Rio de Janeiro, 9 abr. 2002. Opinião, Caderno A, p. 4.

CHAUI, M. Experiência do pensamento: homenagem a MerleauPonty no $\mathrm{XX}^{\circ}$ ano de sua morte. In: CHaui, M. Da realidade sem mistérios aos mistérios do mundo. São Paulo: Brasiliense, 1983.

FOUCAULT, M. História da sexualidade 2: o uso dos prazeres. Rio de Janeiro: Graal, 1990.

HORKHEIMER, M.; ADORNO, T.W. Temas básicos de sociologia. São Paulo: Cultrix, 1978.

HORKHEIMER, M.; ADORNO, T.W. Dialética do esclarecimento: fragmentos filosóficos. Rio de Janeiro: Jorge Zahar, 1985.

KLICKEDUCACAO.COM.BR. Presidente veta projeto que tornava filosofia e sociologia obrigatórias no ensino médio. 2001. Disponível em: <http:www.klickeducacao.com.br/Gestao/TemasPedagogicos/CDA/ Item_View/1,2283,41,00.html>. Acesso em 17 dez. 2001.

MARTINS, J.S. (Org.). (Des)figuraçôes: a vida cotidiana no imaginário onírico da metrópole. São Paulo: Usp/Hucitec, 1996.

MERLEAU-PONTY, M. Sinais. Lisboa: Minotauro, 1962.

MERLEAU-PONTY, M. Ciências do homem e fenomenologia. São Paulo: Saraiva, 1973.

NIETZSCHE, F. Écrits posthumes: 1870-1873. Paris: Gallimard, 1975.

PORCHAT, O. O conflito das filosofias. In: Prado Jr., B. et al. A filosofia e a visão comum do mundo. São Paulo: Brasiliense, 1981.

SOUZA, P.N.P.; SILVA, E.B. Como entender e aplicar a nova LDB. São Paulo: Pioneira, 1997.

THOMPSON, E.P. A miséria da teoria ou um planetário de erros: uma crítica ao pensamento de Althusser. Rio de Janeiro: Zahar, 1981. 